\title{
A Bcr-Abl Inhibitor GNF-2 Attenuates Inflammatory Activation of Glia and Chronic Pain
}

\author{
Gyun Jee Song ${ }^{1,2 t}$, Md Habibur Rahman ${ }^{3+}$, Mithilesh Kumar Jha ${ }^{3,4}$, \\ Deepak Prasad Gupta ${ }^{1,3}$, Sung Hee Park', Jae-Hong Kim ${ }^{3}$, Sun-Hwa Lee ${ }^{5}$, In-Kyu Lee, \\ Taebo Sim ${ }^{7,8}$, Yong Chul Bae ${ }^{9}$, Won-Ha Lee ${ }^{10}$ and Kyoungho Suk ${ }^{3 *}$ \\ 'Department of Medical Science, College of Medicine, Catholic Kwandong University, Gangneung-si, South Korea, \\ ${ }^{2}$ Translational Brain Research Center, International St. Mary's Hospital, Catholic Kwandong University, Incheon, \\ South Korea, ${ }^{3}$ Department of Pharmacology, Brain Science and Engineering Institute, BK21 Plus KNU Biomedical \\ Convergence Program, School of Medicine, Kyungpook National University, Daegu, South Korea, ${ }^{4}$ Department \\ of Neurology, The Johns Hopkins University School of Medicine, Baltimore, MD, United States, ${ }^{5}$ New Drug Development \\ Center, Daegu Gyeongbuk Medical Innovation Foundation, Daegu, and VORONOI Inc., Incheon, South Korea, ${ }^{6}$ Department \\ of Internal Medicine, Division of Endocrinology and Metabolism, School of Medicine, Kyungpook National University, Daegu, \\ South Korea, ${ }^{7}$ KU-KIST Graduate School of Converging Science and Technology, Korea University, Seoul, South Korea, \\ ${ }^{8}$ Chemical Kinomics Research Center, Korea Institute of Science and Technology, Seoul, South Korea, ${ }^{9}$ Department \\ of Anatomy and Neurobiology, School of Dentistry, Kyungpook National University, Daegu, South Korea, ${ }^{10}$ BK21 Plus KNU \\ Creative BioResearch Group, School of Life Sciences, Kyungpook National University, Daegu, South Korea
}

\section{OPEN ACCESS}

Edited by: Morena Zusso,

University of Padua, Italy

Reviewed by:

Zhigang Liu,

Northwest A\&F University, China Katsura Takano,

Osaka Prefecture University, Japan

*Correspondence: Kyoungho Suk

ksuk@knu.ac.kr

†These authors have contributed equally to this work

Specialty section:

This article was submitted to

Neuropharmacology,

a section of the journal

Frontiers in Pharmacology

Received: 25 January 2019 Accepted: 30 April 2019

Published: 20 May 2019

Citation:

Song GJ, Rahman MH, Jha MK,

Gupta DP, Park SH, Kim J-H,

Lee S-H, Lee I-K, Sim T, Bae YC, Lee W-H and Suk K (2019) A Bcr-Abl Inhibitor GNF-2 Attenuates Inflammatory Activation of Glia and Chronic Pain.

Front. Pharmacol. 10:543. doi: 10.3389/fphar.2019.00543
GNF-2 is an allosteric inhibitor of Bcr-Abl. It was developed as a new class of anti-cancer drug to treat resistant chronic myelogenous leukemia. Recent studies suggest that c-Abl inhibition would provide a neuroprotective effect in animal models of Parkinson's disease as well as in clinical trials. However, the role of c-Abl and effects of GNF-2 in glia-mediated neuroinflammation or pain hypersensitivity has not been investigated. Thus, in the present study, we tested the hypothesis that c-Abl inhibition by GNF-2 may attenuate the inflammatory activation of glia and the ensuing pain behaviors in animal models. Our results show that GNF-2 reduced lipopolysaccharide (LPS)-induced nitric oxide and pro-inflammatory cytokine production in cultured glial cells in a c-Abldependent manner. The small interfering ribonucleic acid (siRNA)-mediated knockdown of C-Abl attenuated LPS-induced nuclear factor kappa light chain enhancer of activated $\mathrm{B}$ cell (NF-kB) activation and the production of pro-inflammatory mediators in glial cell cultures. Moreover, GNF-2 administration significantly attenuated mechanical and thermal hypersensitivities in experimental models of diabetic and inflammatory pain. Together, our findings suggest the involvement of c-Abl in neuroinflammation and pain pathogenesis and that GNF-2 can be used for the management of chronic pain.

Keywords: GNF-2, c-Abl, glia, neuroinflammation, pain

\section{INTRODUCTION}

Neuroinflammation is highly associated with several neurodegenerative diseases including Alzheimer's disease (AD), Parkinson's disease (PD), and chronic pain (Katsulov and Mazneikova, 1987; Mosley et al., 2006; Tansey et al., 2007; Calsolaro and Edison, 2016; Chen et al., 2018). The chronic pain pathophysiology is complex and includes peripheral and central neuronal alterations and neuroinflammation. The neuroinflammatory process is characterized by the activation of microglia and astrocytes, macrophage infiltration, release of diverse proinflammatory mediators 
[e.g., nitric oxide (NO), cytokines, and chemokines]. This process leads to neuronal death or neurodegeneration (Frank-Cannon et al., 2009; Song and Suk, 2017). In this regard, important clues to the molecular mechanisms of neuropathic pain may be found by closely examining the microglial inflammatory activation and neuroinflammation (Carniglia et al., 2017; Kiguchi et al., 2017; Chen et al., 2018). Therefore, studies which target inflammatory mediators may provide novel therapeutic approaches for chronic pain management.

Non-receptor tyrosine kinase c-Abl activation is associated with $\mathrm{AD}$ and $\mathrm{PD}$ pathogenesis in human and animal models. c-Abl phosphorylation is robustly increased in brain samples from $\mathrm{AD}$ and $\mathrm{PD}$ patients as well as in animal models of $\mathrm{AD}$, PD, and synucleinopathies (Ko et al., 2010; Imam et al., 2011; Vargas et al., 2018). Furthermore, imatinib or nilotinib, which are FDA-approved c-Abl inhibitors, showed neuroprotective effects when administered in animal models of $\mathrm{PD}$ and $\mathrm{AD}$ (Cancino et al., 2008; Hebron et al., 2013). More recently, activated c-Abl was observed in the spinal cord of G93A-SOD1 transgenic mice, a widely-used model of amyotrophic lateral sclerosis (ALS). This study revealed that the administration of dasatinib (a c-Abl inhibitor) improved the innervation status of neuromuscular junctions (Katsumata et al., 2012). It is quite well known that oxidative stress-induced c-Abl activation leads to nuclear factor kappa light chain enhancer of activated $B$ cell (NF-кB) activation and neuronal death (Xiao et al., 2011). However, most studies have focused on the neuroprotective effects of c-Abl inhibitors and related molecular mechanisms in neurons. Recent findings on pain pathogenesis demonstrate that glial cells, particularly microglia and astrocytes, are an important source of inflammatory mediators fundamentally involved in the pathogenesis of inflammatory and neuropathic pain (Carniglia et al., 2017; Chen et al., 2018). Therefore, it is necessary to study the function of glial c-Abl in the pathogenesis of both inflammatory and neuropathic pain.

GNF-2 is a selective allosteric inhibitor of $\mathrm{Bcr}-\mathrm{Abl}$ (the oncogenic fusion protein of $\mathrm{Bcr}$ and $\mathrm{c}-\mathrm{Abl}$ caused by reciprocal chromosomal translocations), which was developed as an anticancer drug (Zhang et al., 2010; Rossari et al., 2018). GNF-2 binds to the myristate-binding site of $\mathrm{c}-\mathrm{Abl}$, leading to improved pharmacokinetic properties (Fabbro et al., 2010; Zhang et al., 2010). GNF-2 is a very selective non-ATP competitive inhibitor of Bcr-Abl and c-Abl. Unlike other inhibitors, it does not show activity against many other kinases such as fms-like tyrosine kinase 3, platelet-derived growth factor receptor, Janus kinase1 , tyrosine-protein kinase Met. Therefore, in this study, we used GNF-2 to assess the effect of c-Abl on neuroinflammation and associated pain pathogenesis using multiple pain models. It has been reported that reactive microglia release a various array of toxic molecules including pro-inflammatory cytokines, NO, and superoxide, which have been shown to play a complex role in the pathogenesis of neuropathic pain. However, the effects of c-Abl inhibition by GNF-2 on neuroinflammation and associated chronic pain pathogenesis remain elusive. Thus, in the present study, we investigated the role of $\mathrm{c}$-Abl in the inflammatory activation of glia and their contribution to the pathogenesis of inflammatory and neuropathic pain by the in vitro and in vivo application of the Bcr-Abl inhibitor GNF-2.

\section{MATERIALS AND METHODS}

\section{Materials}

GNF-2 and methylated GNF-2 compounds were prepared as described previously (Adrian et al., 2006). Lipopolysaccharide (LPS) was purchased from Sigma-Aldrich. It was obtained from Escherichia coli 0111:B4 prepared by phenolic extraction and gel filtration chromatography. Recombinant mouse interferon- $\gamma$ $(I F N-\gamma)$ protein was purchased from R\&D Systems. The c-Abl siRNA (1:1 mix of siRNA \#2 and \#3) and control siRNA were purchased from Genolution Pharmaceuticals (Seoul, South Korea); siCont- 5'-CCUCGUGCCGUUCCAUCAGG UAGUU-3', siAbl-\#2, 5'-GCAACAAGCCCACUAUCUAUU-3', siAbl-\#3, 5'-UGAUGAAGGAGAUCAAACAUU-3'.

\section{Cell Culture}

BV-2 immortalized murine microglial cell line was maintained in Dulbecco's modified Eagle's medium (DMEM) containing $5 \%$ heat-inactivated fetal bovine serum (FBS) and $50 \mathrm{mg} / \mathrm{ml}$ gentamicin at $37^{\circ} \mathrm{C}$. For mouse primary mixed glial cells (MGCs) culture, the brains of 3-day old C57BL6 mice were isolated and homogenized and mechanically disrupted by a nylon mesh. The MGCs were seeded in poly-L-lysine-coated culture flasks with DMEM containing 10\% FBS, $100 \mathrm{U} / \mathrm{ml}$ of penicillin, and $100 \mu \mathrm{g} / \mathrm{ml}$ of streptomycin (Gibco, Grand Island, NY, United States) and allowed to grow at $37^{\circ} \mathrm{C}$ in a humidified atmosphere with $5 \% \mathrm{CO}_{2}$. Culture medium was changed initially after 5 days and then changed every 3 days. After 14 days of culture, MGCs (mixed microglial and astrocytes) were prepared by trypsinization, as previously described (Song et al., 2016). The collected cells were further plated using the same media condition and used for experiments.

\section{Nitric Oxide Production}

The BV-2 cells $\left(4 \times 10^{4}\right.$ cells/well in 96-well plates $)$ were treated with $100 \mathrm{ng} / \mathrm{ml}$ of LPS and the level of NO production was assessed by measuring the amount of nitrite as previously described (Lee et al., 2009). Briefly, After 24-h of incubation, $50 \mu \mathrm{l}$ of the cell culture media was mixed with an equal volume of a Griess reagent $(0.1 \%$ naphthylethylenediamine dihydrochloride and $1 \%$ sulfanilamide in $5 \%$ phosphoric acid) in a 96-well microtiter plate. Absorbance at $540 \mathrm{~nm}$ was measured on a microplate reader. Sodium nitrite was used as the standard curve to calculate NO concentration.

\section{Assessment of Cell Viability}

Both BV-2 microglia and primary MGCs $\left(4 \times 10^{4}\right.$ cells/well in 96-well plates) were used to measure cell viability using 3-(4, 5 dimethylthiazol-2-yl)-2, 5-diphenyltetrazolium bromide (MTT; Sigma-Aldrich) assay, as previously described (Song et al., 2016). After $24 \mathrm{~h}$ of LPS treatment, the culture media was removed and MTT $(0.5 \mathrm{mg} / \mathrm{ml}$ in PBS) was added to the cells, which were then incubated at $37^{\circ} \mathrm{C}$ for $2 \mathrm{~h}$ in a $5 \% \mathrm{CO}_{2}$ incubator. The insoluble 
formazan crystals were completely dissolved in DMSO. The absorbance at $570 \mathrm{~nm}$ was measured using a microplate reader.

\section{Enzyme-Linked Immunosorbent Assay (ELISA) for TNF- $\alpha$}

The BV-2 cells or primary cells were treated with LPS either in the presence or absence of GNF-2 for $24 \mathrm{~h}$. The concentration of TNF- $\alpha$ protein in the culture media was assessed using a rat monoclonal anti-mouse TNF- $\alpha$ antibody (capture antibody), and a goat biotinylated polyclonal antimouse TNF- $\alpha$ antibody (detection antibody), as described in the product manual (ELISA development reagent; R\&D systems, Minneapolis, MN, United States). The recombinant TNF- $\alpha$ protein was used as a standard.

\section{Small Interfering Ribonucleic Acid (siRNA)-Mediated Knockdown of the c-Abl Gene}

Cells were transfected with siRNAs using Lipofectamine ${ }^{\mathrm{TM}}$ iMAX (Invitrogen, Carlsbad, CA, United States), based on the manufacturer's instructions. The cells were used after $48 \mathrm{~h}$ of transfection.

\section{Traditional and Real-Time Reverse Transcription Polymerase Chain Reaction (RT-PCR)}

Total ribonucleic acid (RNA) was extracted from the treated cells or tissues (spinal cord and brain) using TRIZOL reagent (Invitrogen, Carlsbad, CA, United States). Reverse transcription (RT) was conducted using the Superscript II reverse transcriptase (Invitrogen) and an oligo (dT) primer. Traditional PCR amplification was done using specific primer sets at $55-60^{\circ} \mathrm{C}$ as annealing temperature and 25-32 cycles in a C1000 Touch Thermal Cycler (Bio-Rad, Richmond, CA, United States). PCR products with ethidium bromide were electrophoresed on a $1 \%$ agarose gel, and bands were observed under ultraviolet light for analysis. Real-time PCR was performed using One Step SYBR PrimeScript RT-PCR Kit (Takara Bio, Otsu, Shiga, Japan), according to the manufacturer's instructions, followed by detection using the ABI Prism 7000 Sequence Detection System (Applied Biosystems, California, CA, United States). Glyceraldehyde 3-phosphate dehydrogenase (GAPDH) was used as an internal control. The primer sequences were designed based on published complementary deoxyribonucleic acid (cDNA) sequences (Table 1).

TABLE 1 | DNA sequences of the primers used for RT-PCR.

\begin{tabular}{lll}
\hline $\begin{array}{l}\text { Target } \\
\text { genes }\end{array}$ & Forward primer $\left(\mathbf{5}^{\prime}-\mathbf{-} \mathbf{3}^{\prime}\right)$ & Reverse primer $\left(\mathbf{5}^{\prime}-\mathbf{-} \mathbf{3}^{\prime}\right)$ \\
\hline C-Abl & GAGCCTGGCCTACAACAAGT & TGTCCAGTGCATCGCTTTCT \\
TNF- $\alpha$ & CATCTTCTCAAAATTCGAGTACAA & ACTTGGCAGATTACCTCAG \\
IL-1 $\beta$ & GCAACTGTCCTGAACTC & CTCGGAGCCTGTAGTGCA \\
IL-6 & AGTTGCCTTCTTGGGACTGA & TCCACGATTCCCAGAGAAC \\
GAPDH & ACCACAGTCCATGCCATCAC & TCCACCACCCTGTTGCTGTA
\end{tabular}

\section{Western Blotting Analysis}

Cells or brain tissues were lysed in $300 \mu \mathrm{l}$ of lysis buffer [150 mM sodium chloride, 1\% Triton X-100, 1\% sodium deoxycholate, $0.1 \%$ sodium dodecyl sulphate (SDS), $50 \mathrm{mM}$ Tris$\mathrm{HCl}$ ( $\mathrm{pH}$ 7.5), 2 mM EDTA] containing mixture of Halt ${ }^{\mathrm{TM}}$ protease and phosphatase inhibitors $(1 \times)$ (Thermo Fisher Scientific). The brain tissues were individually homogenized and then centrifuged at $13,400 \times g$ at $4^{\circ} \mathrm{C}$ for $15 \mathrm{~min}$. Protein concentration was determined using the Pierce BCA protein assay kit (Thermo Fisher Scientific). Bovine serum albumin was used as the standard. Proteins $(20-30 \mu \mathrm{g})$ for each sample were separated using $12 \%$ sodium dodecyl sulfate-PAGE and transferred to polyvinylidene fluoride filter membranes (BioRad) by the semi-dry electroblotting method. The membranes were blocked with 5\% skim milk and incubated sequentially with the following primary antibodies against either c-Abl (rabbit monoclonal antibody, 1:1000; Santa Cruz), p-p65, p-65, p-ІкB, IКB (rabbit monoclonal antibody, 1:1000; Cell Signaling), TNF$\alpha$ (rat anti-mouse monoclonal antibody, 1:500; Millipore) or $\alpha$-tubulin (mouse monoclonal antibody, 1:2000; Sigma-Aldrich) and horseradish peroxidase-conjugated secondary antibodies (anti-rabbit or mouse IgG antibody; Cell Signaling), followed by chemiluminescence detection (Thermo Fisher Scientific).

\section{Animals and Maintenance}

All experiments were conducted in accordance with approved animal protocols and guidelines established by the Animal Care Committee of Kyungpook National University. All efforts were made to reduce the number of animals and their sufferings. Agematched male C57BL/6 mice (8-10 weeks old) were supplied by Samtako Bio (South Korea). Mice were housed in the groups of three to five per cage under standard condition using a 12h light/dark cycle (lights on 07:00-19:00) at a constant ambient temperature of $23 \pm 2{ }^{\circ} \mathrm{C}$. Each individual animal was used for a single experiment.

\section{Neuroinflammation Model Based on Intraperitoneal LPS Injection}

Lipopolysaccharide was administered to evoke neuroinflammation in mice as described previously (Jo et al., 2017). Mice were injected a single dose of vehicle or LPS (5 mg/kg) intraperitoneally. Phosphate buffered saline (PBS) was used as vehicle and administered the same volume. Mice were sacrificed $48 \mathrm{~h}$ after injection and brain tissues collected for further analysis.

\section{The Complete Freund's Adjuvant (CFA)-Induced Chronic Inflammatory Pain Model}

Chronic inflammation in mice was induced by a single dose of CFA injection, as described previously (Jha et al., 2015). Briefly, mice were gently anesthetized with $5 \%$ of isoflurane for induction and $2 \%$ for maintenance. They received CFA $(30 \mu \mathrm{l}$, $0.5 \mathrm{mg} / \mathrm{ml}$; Sigma-Aldrich) unilaterally in their left hind paws (ipsilateral paws) by intraplantar injections. Mice in the control group received an equal amount of saline in their left hind 
paws. Pain behaviors were assessed before and up to 5 days post-CFA administration.

\section{Measurement of CFA-Induced Paw Edema}

Complete Freund's adjuvant-induced paw edema was assessed by the measurement of paw thickness. One experimenter, who was blinded to the treatment conditions, handled and tested all the animals. The dorsoventral thickness of the middle portions of the hind paws were measured using a caliper, as described previously (Jha et al., 2015).

\section{Streptozotocin (STZ)-Induced Diabetes Model}

The mouse model of diabetes was generated as described previously (Rahman et al., 2016). Briefly, type-1 diabetes was induced by an intraperitoneal administration of STZ $(150 \mathrm{mg} / \mathrm{kg}$ body weight; Sigma-Aldrich), prepared in $0.1 \mathrm{M}$ citrate buffer $(\mathrm{pH} 4.5)$. An equal amount of citrate buffer was injected into control animals. Glycaemia level was tested in blood samples collected from the tail vein 3 days post-STZ injection by using an SD CodeFree ${ }^{\mathrm{TM}}$ glucometer (SD Biosensor Inc., Suwonsi, South Korea). Mice with fasting blood glucose levels over $260 \mathrm{mg} / \mathrm{dl}$ were considered diabetic and used for further study.

\section{Behavioral Test for Pain}

Before the actual test, mice were allowed to familiarize the experimenter, testing room, and equipment for at least 1 week. Paw withdrawal thresholds (PWTs) in response to mechanical stimulations were measured at different time points following CFA and STZ injection. The mechanical sensitivity was examined using calibrated Von Frey filaments (Bioseb ${ }^{\mathrm{TM}}$, Chaville, France), as described previously (Rahman et al., 2016). PWT was calculated from five consecutive withdrawal responses using Dixon's up-down method. Thermal hyperalgesia is defined as a decrease in paw withdrawal latencies (PWL) in response to a noxious thermal stimulus. The thermal sensitivity was tested using the Hargreaves' Plantar Test Analgesy-Meter (Ugo Basile), as previously described (Jha et al., 2015). To obtain the mean PWL values, tests were repeated at least three times and averaged with $5 \mathrm{~min}$ intervals between tests to avoid heatinduced sensitization. One experimenter, who was unaware of the experimental conditions, handled and examined all the animals.

\section{Immunohistochemistry and Histopathology}

Mice were deeply anesthetized and then subjected to intracardiac perfusion-fixation through the aorta with 0.1 M PBS followed by $4 \%$ paraformaldehyde dissolved in $0.1 \mathrm{M}$ PBS. The tissues were further post-fixed in the same paraformaldehyde overnight. Tissues were washed with $0.1 \mathrm{M}$ PBS and cryoprotected in 30\% sucrose in $0.1 \mathrm{M}$ PBS overnight at $4^{\circ} \mathrm{C}$. Tissues were embedded in frozen section compound (FSC 22 Clear; Leica), and a cryostat was used to prepare $20 \mu \mathrm{m}$-thick cross-sections for the spinal cord tissues and $30 \mu \mathrm{m}$-thick coronal sections for the brain tissues. Tissue sections or fixed cells were then blocked with $1 \%$ bovine serum albumin or normal serum in $0.3 \%$ Triton X-100 for $60 \mathrm{~min}$ at room temperature. For immunofluorescence staining, tissue sections were incubated with the following primary antibodies against c-Abl (rabbit, 1:100; Santa Cruz), Iba-1 (goat, 1:200; Novus Biologicals, Littleton, CO, United States), GFAP (mouse, 1:500; BD Biosciences), inducible nitric oxide synthase (iNOS) antibody (mouse, 1:200 dilution; BD Transduction Laboratories) or NF- $\mathrm{KB}$ p65 (rabbit, 1:500) overnight at $4^{\circ} \mathrm{C}$, and then incubated with $\mathrm{Cy} 3-$ or FITC-conjugated secondary antibodies (1:200; Jackson ImmunoResearch, West Grove, PA, United States). Slides were washed three times with 0.1 M PBS in $0.3 \%$ Triton X-100, and mounted with Vectashield mounting medium (Vector Laboratories, Burlingame, CA, United States) using glass cover-slips, and visualized under a fluorescence microscope (Leica Microsystems, DM2500, Wetzlar, Germany).

\section{Quantification and Statistical Analysis}

Statistical analysis was performed using either a Student's $t$ test or a one/two-way ANOVA with Dunnett's multiple-comparisons test using GraphPad Prism (version 5.01). Differences with $p$-values $<0.05$ were considered to be statistically significant. For the immunohistochemical analysis, 5-6 microscopic images were chosen randomly for statistical analysis. For the measurement of either immunofluorescence or western blot band intensities, the area of the whole image or each band was selected, and the mean intensity was measured using the ImageJ software (National Institutes of Health, Bethesda, MD, United States). The background intensity of the band was also measured and deducted from the values obtained.

\section{RESULTS}

\section{GNF-2 Inhibits LPS-Induced Inflammatory Activation of Glial Cells in Culture}

c-Abl is activated by oxidative stress and its activation in neurons increases NF- $\mathrm{KB}$ activation leading to neuronal death (Xiao et al., 2011). In this study, we examined whether c-Abl is involved in the process of inflammatory microglial activation. To investigate the role of c-Abl in inflammatory microglial activation, BV-2 immortalized mouse microglial cell line was stimulated with LPS after GNF-2 pre-treatment (Figure 1A). GNF-2 significantly inhibited LPS-induced NO (Figure 1B) and TNF- $\alpha$ production (Figure 1D) in a dose-dependent manner and GNF-2 did not show any apparent cytotoxicity in the microglia (Figure 1C). Similarly, exposure of BV2 microglia to LPS significantly increased the expression of $I L-1 \beta$ mRNA, whereas GNF-2 treatment markedly attenuated LPS-induced upregulation of $I L-1 \beta$ (Figure 1E). GNF-2 treatment significantly reduced LPS-induced NF- $\kappa \mathrm{B}$ activation in BV-2 microglial cells. Notably, LPS-induced NF- $\kappa$ B activation (phosphorylation of ІкB and p65) was decreased in microglia following GNF-2 treatment (Figures 1F-I). NF-kB activation is associated with nuclear translocation of the p65, a component of the NF- $\mathrm{kB}$ complex (Tanaka and Iino, 2016). LPS-induced nuclear translocation 


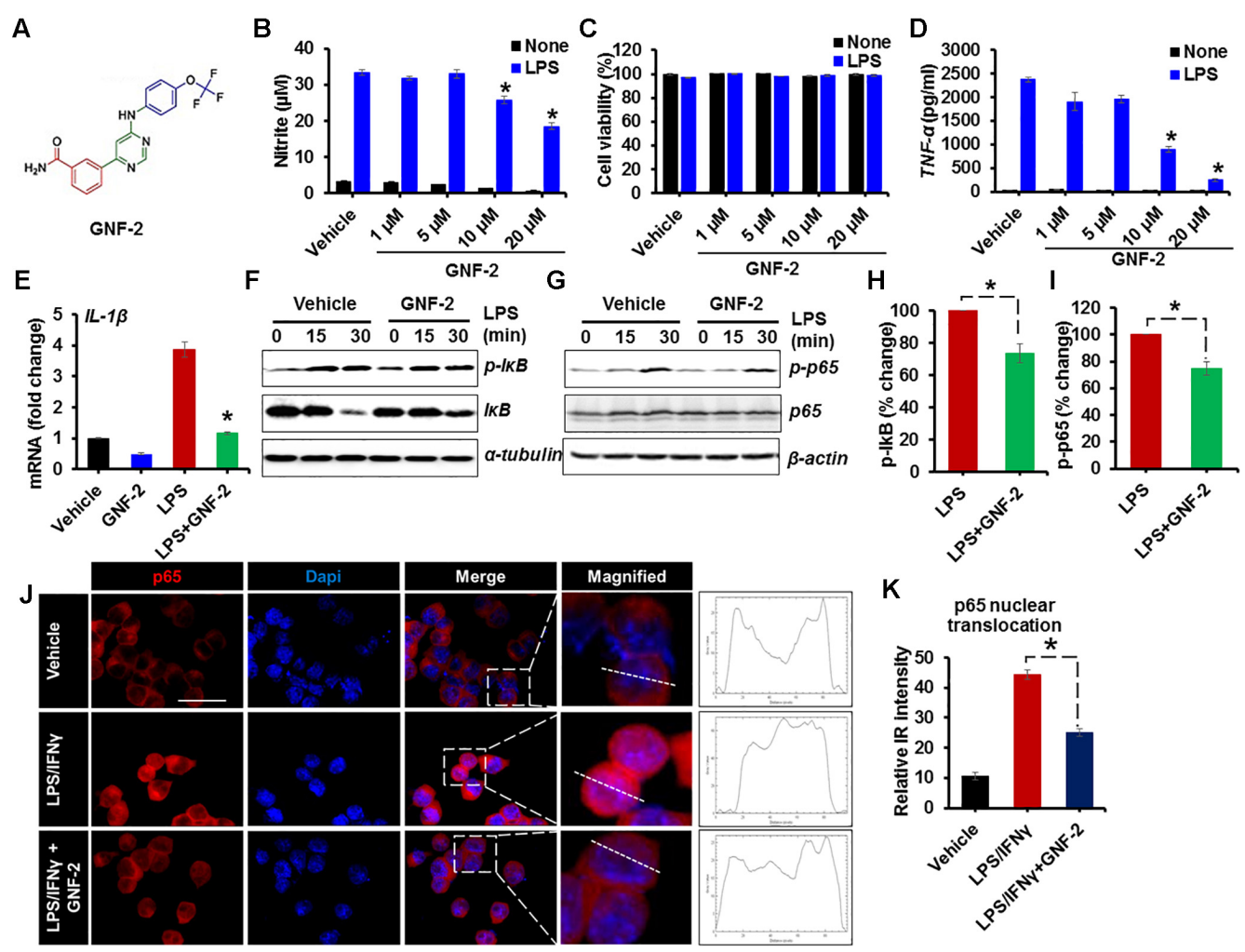

FIGURE 1 | GNF-2 inhibits LPS-induced inflammatory activation of microglia. (A) Chemical structure of GNF-2. (B) The dose-dependent effect of GNF-2 on BV-2 cells in either the presence or absence of LPS (100 ng/ml) stimulation. (C) The cytotoxicity was measured using the MTT assay $24 \mathrm{~h}$ after treatment with LPS and the indicated compound concentration. (D) TNF- $\alpha$ release was measured by ELISA in BV-2 cells treated with LPS and GNF-2 for 24 h. (E) Real-time PCR for IL-1 $\beta$ mRNA expression in BV-2 cells treated with LPS or GNF-2 (10 $\mu \mathrm{M})$ for $24 \mathrm{~h}$. (F,G) Western blot analysis for the phosphorylation of IkB (F) or NF-kB p65 (G) in BV-2

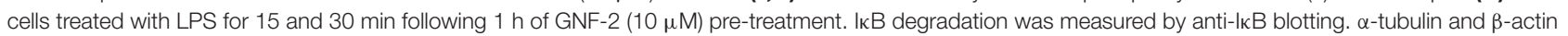
were used as loading control. (H) Quantification for the relative \% change in p-IkB at 30 min after LPS or GNF-2 treatment. (I) Quantification for the relative intensity for p-p65 western blot bands at 30 min after LPS or GNF-2 treatment. (J) Immunocytochemistry for p65 in BV-2 cells in either presence or absence of GNF-2 with LPS treatment. Fluorescence intensity profile for p65 across a transverse section of one cell is presented adjacent to the magnified images. The dotted line shows the cross section of the single cell for the fluorescence intensity profile. (K) Quantification for the relative IR intensity for the p65 nuclear translocation is presented in the adjacent graph. Nuclear translocation of p65 IF intensity was measured for 10 randomly selected cells from each group with ImageJ. Data are presented as mean \pm SEM. ${ }^{*} p<0.05$ vs. LPS from ANOVA and unpaired two-tailed Student's $t$ test; $n=3$ for each group. Scale bar, $50 \mu \mathrm{m}$.

of p65 was measured in BV-2 cells after pretreatment with GNF-2. GNF-2 significantly reduced nuclear p65 expression (Figures 1J,K). These findings suggest that GNF-2 attenuates inflammatory activation of microglia induced by LPS through inhibition of c-Abl activity.

\section{Knockdown of c-Abl Expression Inhibits LPS-Induced Glial Activation}

It has been documented that the expression of active c-Abl in adult mouse forebrain neurons induces severe and progressive neurodegeneration in the Cornu Ammonis 1 (CA1) region of the hippocampus and reactive gliosis (Schlatterer et al., 2011). However, the function of $\mathrm{c}$-Abl in microglia upon inflammatory stimulation has not been studied yet. To examine the role of $\mathrm{c}-\mathrm{Abl}$ expression in microglia following inflammatory stimulation, BV-2 cells were transfected with siRNA for c-Abl knockdown and the inflammatory activation of microglia was examined (Figures 2A,B). The knockdown of the c-Abl gene expression (more than 50\%) in BV-2 cells significantly attenuated LPS-induced nitric oxide production (Figure 2C) as well as the expression of pro-inflammatory TNF- $\alpha$ mRNA (Figure 2D).

\section{Verification of the Anti-inflammatory Effect of GNF-2 in Primary Microglia and Astrocytes}

To determine whether the anti-inflammatory effect of GNF-2 is also observed in primary microglia and astrocytes, primary MGCs were treated with various inflammatory stimuli including LPS, TNF- $\alpha$, or combination of LPS and interferon-gamma $(I F N-\gamma)$. As in the BV-2 cells, GNF-2 significantly inhibited LPS-induced NO release. In addition, the anti-inflammatory effect of GNF-2 in MGC upon stimulation with recombinant TNF- $\alpha$ protein, an alternative potent inflammatory stimulus, was also assessed. Similarly, GNF-2 significantly inhibited TNF$\alpha$-induced NO production in primary glial cells (Figure 3A). Further, these findings led us to investigate whether GNF-2 can 

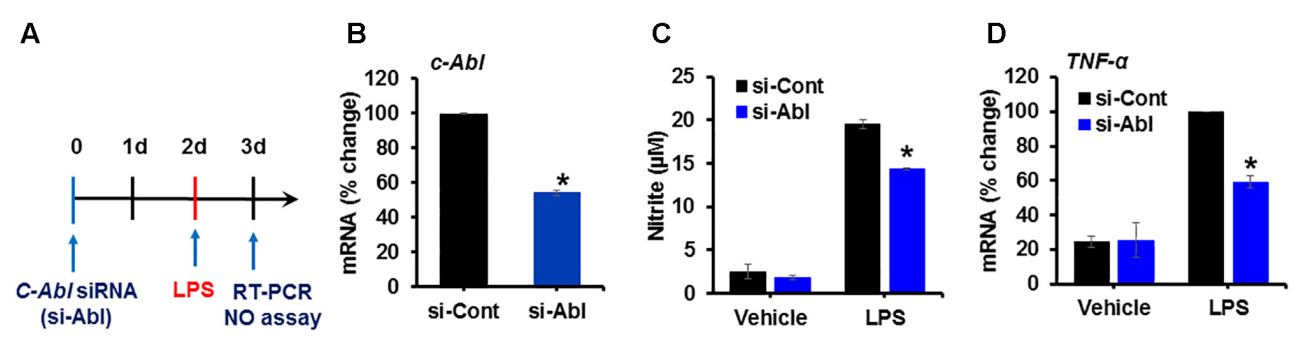

FIGURE 2 | Knockdown of c-Abl expression inhibits LPS-induced inflammatory activation of microglia. (A) Experimental scheme. BV-2 cells were transfected with siRNA for the c-Abl gene and then treated with LPS (100 ng/ml) on day 2. Real-time PCR was performed on BV-2 cells on day 3 after transfection. (B) c-Abl gene expression was significantly reduced after siRNA transfection. (C) Nitric oxide (NO) production was measured in cells treated with LPS for $24 \mathrm{~h}$ after siRNA transfection. (D) TNF- $\alpha$ mRNA measured by real-time RT-PCR. si-Cont, control siRNA, si-Abl, siRNA for c-Abl gene knockdown. * $p<0.05$ vs. si-Cont from ANOVA.

inhibit LPS and IFN- $\gamma$-induced production of pro-inflammatory mediators in primary glial cells or not. We found that GNF-2 pre-treatment dramatically suppressed such upregulation of $I L-1 \beta$ mRNA expression (Figure 3B). However, pre-treatment with a methylated GNF-2 analog, mGNF-2 (methylation of the aniline nitrogen at the $\mathrm{C} 4$ position of the pyrimidine) (Choi et al., 2009), did not suppress LPS-induced NO production. This is because methylation of GNF-2 abolished the binding specificity of GNF-2 for c-Abl (Choi et al., 2009), suggesting that the effect of GNF-2 is highly specific for c-Abl (Figure 3C). Subsequently, the effects of GNF-2 on NF- $\kappa$ B activation after LPS and IFN- $\gamma$ stimulation was examined in MGCs pretreated with GNF-2. The pre-exposure of MGCs to GNF-2 strongly inhibited LPS and IFN- $\gamma$-induced NF- $\kappa$ B activation. This was assessed by western blot analyses of phosphorylatedp65 and -IкB protein (Figures 3D-F). Furthermore, knocking down the c-Abl gene by siRNA also significantly inhibited LPS/IFN- $\gamma$-induced NO production (Figure 3G), TNF- $\alpha$ mRNA expression (Figures 3H,I), and NF- $\kappa \mathrm{B}$ activation (Figures 3J-L) in the primary MGC. Taken together, these findings suggest that GNF-2 may have a potent anti-inflammatory role in gliamediated neuroinflammation.

\section{Anti-inflammatory Effects of GNF-2 in a Neuroinflammation Model}

To investigate the role of $\mathrm{c}-\mathrm{Abl}$ in neuroinflammation, a mouse model of neuroinflammation induced by the intraperitoneal (IP) administration of LPS was used. First, the expression of c-Abl at the level of the mRNA and protein was examined by using RT-PCR and immunostaining in brain tissues isolated from LPSinjected mice. RT-PCR analysis revealed enhanced expression of $c$ - $A b l$ mRNA after 2 days post-LPS injection (Figures 4A,B). Similarly, immunofluorescence analysis showed a substantial upregulation of $\mathrm{c}-\mathrm{Abl}$ protein in the brain cortex following LPS administration (Figure 4C). Co-immunostaining analysis revealed that $\mathrm{c}-\mathrm{Abl}$ is found to be expressed in Iba-1-positive microglial cells, particularly in hyperactivated microglia with amoeboid shape (indicated by arrows in Figure 4C). The effect of GNF-2 on microglial activation was further tested in vivo using a mouse model of LPS-induced neuroinflammation. As shown in Figure 5A, GNF-2 treatment in the pre-treatment group started $24 \mathrm{~h}$ before LPS injection. It was administered daily for three more days. The mice were then sacrificed and examined for neuroinflammation. To evaluate the anti-inflammatory effect of GNF-2 in vivo, the expression of pro-inflammatory cytokines was measured in brain tissues at the levels of both mRNA and protein. The expression levels of TNF- $\alpha$ and $I L-1 \beta$ mRNA were significantly diminished following GNF-2 pre-treatment (Figures 5B,G). Similarly, GNF-2 pre-treatment significantly reduced the expression of TNF- $\alpha$ protein induced by LPS (Figures $\mathbf{5} \mathbf{C}, \mathbf{H}$ ). Our in vitro data showed a potent inhibitory effect of GNF-2 on NO production by glial cells upon inflammatory stimulation. To confirm whether GNF2 can reduce the expression level of iNOS in the mouse brain following LPS administration, immunostaining of brain tissue sections isolated from mice treated with LPS and GNF2 was performed. The immunostaining analyses revealed an upregulation of iNOS immunoreactivity in the brain cortex after $48 \mathrm{~h}$ of LPS injection when compared with vehicleinjected control animals; the immunoreactivity was significantly attenuated in GNF-2-injected mice (Figures 5D,I). Further, the levels of Iba-1 and GFAP immunoreactivity were assessed, since they are molecular markers of microglia and astrocyte activation (Rahman et al., 2016). Upon LPS injection, a significant increase in the number of Iba-1-positive microglial cells was observed in the cortex of mice brain, where microglia displayed enhanced Iba-1 immunoreactivity with short and thick processes when compared to control mice (Figures 5E,J). These morphological features of the microglia and the increased Iba-1 immunoreactivity in the cortex were attenuated in mice treated with GNF-2. Similarly, the GFAP-positive astrocytes in the cortex of LPS-injected mice showed enhanced immunoreactivity and hypertrophic morphology in comparison to that in the cortex of the vehicle-injected control animals; the immunoreactivity and hypertrophic morphology were both significantly attenuated in GNF-2-treated mice (Figures 5F,K). These findings suggest that the intraperitoneal administration of GNF-2 has a potent antiinflammatory effect on LPS-induced neuroinflammation. The potential brain uptake mechanism of small-molecule compounds is based on physiochemical and molecular properties (Mikitsh and Chacko, 2014). In line with these parameters, GNF-2 is a small-molecule compound with comparatively low molecular weight (374.323) and has a high lipophilicity (Adrian et al., 2006), 


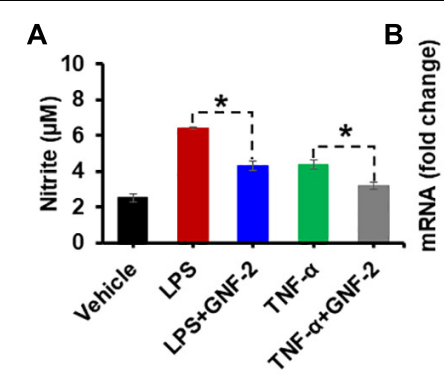

E
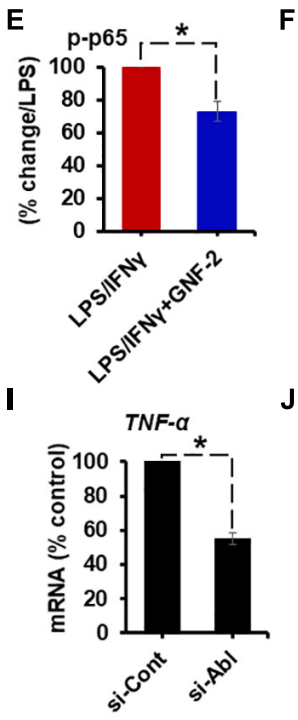

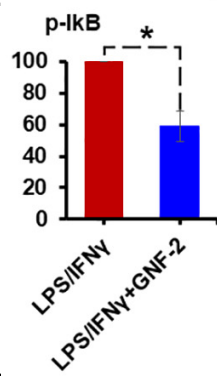

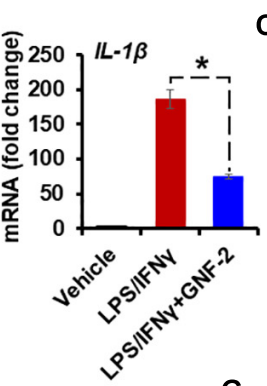

G

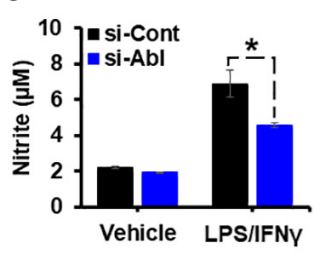

D

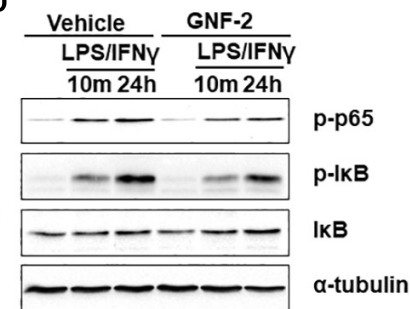

H
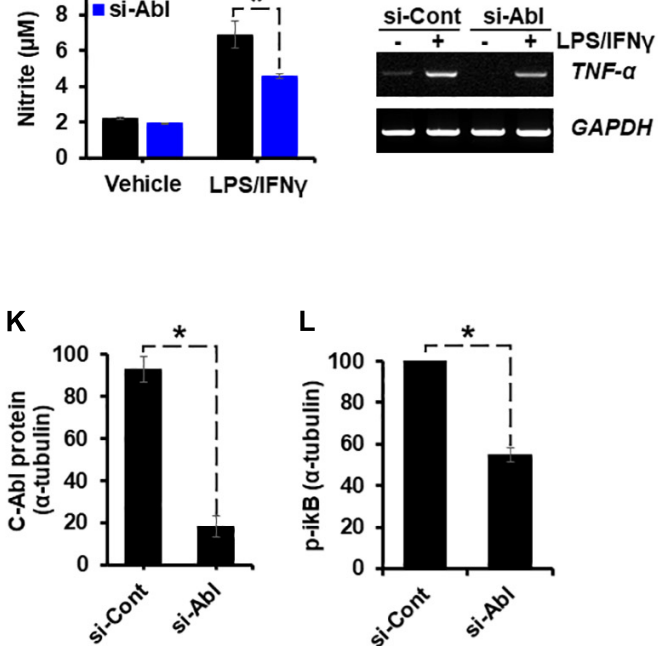

FIGURE 3 | Verification of the anti-inflammatory effect of GNF-2 in primary microglia and astrocytes. Mouse mixed glial cells (MGC) were plated on 96-well plates. (A) Nitric oxide (NO) production induced by LPS $(1 \mu \mathrm{g} / \mathrm{ml})$ or TNF- $\alpha(10 \mu \mathrm{g} / \mathrm{ml})$ was significantly reduced by GNF-2 treatment. (B) IL-1 $\beta$ mRNA expression induced by LPS $(1 \mu \mathrm{g} / \mathrm{ml})$ and IFN- $\gamma(50 \mathrm{U} / \mathrm{ml})$ was significantly reduced by GNF-2 treatment. (C) NO production induced by LPS (1 $\mu \mathrm{g} / \mathrm{ml})$ and IFN- $\gamma(50 \mathrm{U} / \mathrm{ml}) \mathrm{was}$ significantly reduced by GNF-2 treatment but not by mGNF-2, the methylated version of GNF-2. (D) NF-кB activation was reduced by GNF-2 pre-treatment for 1 h. Western blotting was performed to measure phosphorylation of $\mathrm{p} 65$ and $\mathrm{I}_{\mathrm{K}} \mathrm{B}$ in MGC after treatment with the indicated reagents. (E,F) Quantification for the relative $\%$ change of p-p65 (E) and p-IkB (F) at 24 h after LPS/IFN- $\gamma$ or GNF-2 treatment. (G-L) MGC were transfected with siRNA for the c-Abl gene and incubated for 2 days. Cells were then treated with LPS and IFN- $\gamma$ for $24 \mathrm{~h}$. siRNA-mediated knockdown of the c-Abl gene significantly reduced LPS/IFN- $\gamma$-induced NO production (G), TNF- $\alpha$ mRNA expression (H). (I) Quantification for the relative \% change of TNF- $\alpha$ mRNA following LPS/IFN- $\gamma$ treatment presented in the adjacent graph. (J) C-Abl expression and phosphorylation of $I_{\kappa} B$, measured by Western blot analysis. (K) Quantification for the relative protein expression of c-Abl after $\mathrm{C}-\mathrm{Abl}$ gene knockdown following LPS/IFN- $\gamma$ treatment. (L) Quantification for the relative protein expression for p-IkB after c-Abl gene knockdown following LPS/IFN- $\gamma$ treatment. si-C, control siRNA; si-A, siRNA for c-Abl gene knockdown. Alpha-tubulin was used as the protein loading control. Data are presented as mean \pm SEM. ${ }^{*} p<0.05$ from ANOVA and unpaired two-tailed Student's $t$ test; $n=3$ for each group. ns, not significant.

which are important criteria for BBB permeability (Mikitsh and Chacko, 2014). In addition, several studies have demonstrated that mice injected with LPS intraperitoneally show blood-brain barrier (BBB) disruption and increased permeability (Jangula and Murphy, 2013; Banks et al., 2015; Varatharaj and Galea, 2017). Thus, BBB disruption and increased permeability in the LPS model may facilitate GNF-2 transportation from circulation to the central nervous system (CNS), thereby enabling the anti-inflammatory effects of peripherally administered GNF2 on CNS events.

\section{GNF-2 Ameliorates Inflammatory Pain Hypersensitivity}

Our in vitro and in vivo studies strongly indicated that treatment with GNF-2 suppresses neuroinflammation. Based on these observations, the pharmacological efficacy of GNF-2 was validated in a mouse model of CFA-induced chronic inflammatory pain. This model recapitulates several key inflammatory phenotypes including paw edema and proinflammatory cytokine release in the hind paw and spinal cord tissues, which has been suggested as a mechanistic consequence of peripheral and CNS pathology of CFA-induced pain hypersensitivity (Jha et al., 2014, 2016). To investigate whether intraperitoneally administering GNF-2 in this mouse model could inhibit CFA-induced pain hypersensitivity (Figure 6A), a single injection of GNF-2 (10 $\mathrm{mg} / \mathrm{kg}$ body weight) was administered 30 min before CFA-administration. GNF-2-injected mice showed significantly diminished CFA (10 mg/kg)-induced paw edema formation (Figure 6B), the development of thermal hyperalgesia (Figure 6C), and mechanical allodynia (Figure 6D). However, the analgesic effect of $1 \mathrm{mg} / \mathrm{kg}$ GNF-2 
A

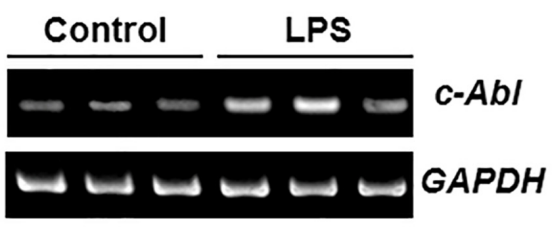

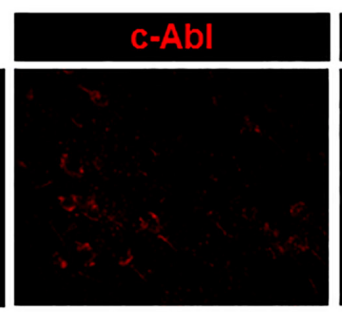

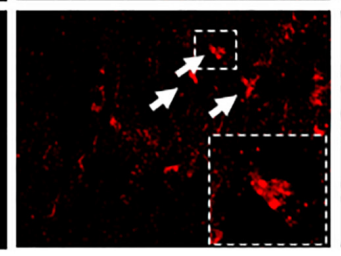

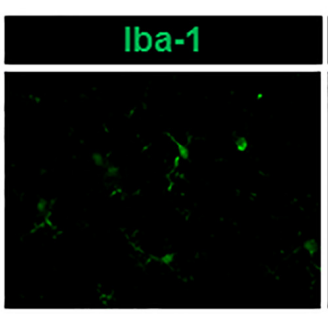

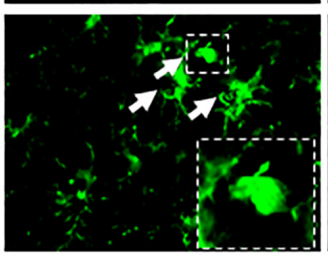

B

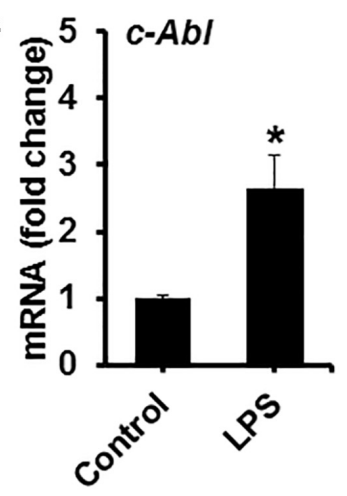

FIGURE 4 | Expression of c-Abl in brain tissues after LPS injection. (A) The expression of c-Abl mRNA in brain tissues $48 \mathrm{~h}$ after the intraperitoneal injection of LPS was assessed by conventional RT-PCR. (B) Quantification for the c-Abl mRNA expression normalized to GAPDH. (C) Double immunostaining showed that c-Abl (red) expression co-localized with lba-1 (green)-positive microglia in the cortex area of mouse brain $48 \mathrm{~h}$ post-LPS injection. Arrows indicate the double-labeled cells. The enlarged amoeboid shape of microglia is magnified as indicated in the dotted area. The nuclei were stained with DAPI (blue). ${ }^{*} p<0.05$ vs. the vehicle-treated control animals; unpaired two-tailed Student's $t$ test; $n=3$ for each group; data are presented as mean \pm SEM. Scale bar, $100 \mu m$.

was partial (Figures 6C,D). The withdrawal latency in response to thermal stimuli and the withdrawal threshold in response to mechanical stimuli were unchanged in the contralateral hind paws following CFA and GNF-2 treatment (data not shown). These results demonstrate the crucial role of $\mathrm{c}-\mathrm{Abl}$ in chronic inflammatory pain.

\section{GNF-2 Attenuates Diabetes-Induced Neuroinflammation and Pain Hypersensitivity}

To investigate the role of GNF-2 in neuroinflammation and pain hypersensitivity, an STZ-induced painful diabetic mouse model was also used. The mRNA and protein levels of c-Abl were first examined in spinal cord tissues isolated from mice 2 weeks after STZ injection using RT-PCR and immunostaining (Figure 7A). RT-PCR analysis revealed that the induction of diabetes significantly increases the expression of c-Abl mRNA in the spinal cord (Figures 7B,C). Similarly, immunofluorescence analysis showed a substantial upregulation of the $\mathrm{c}$-Abl protein in the dorsal horn of the lumbar segment of the spinal cord (Figure 7D). In addition, c-Abl was expressed in GFAP-positive astrocytes, particularly those located in the lamina I region of the diabetic spinal cord. Subsequently, the expression levels of pro-inflammatory cytokines and glial activation were examined in the spinal cord of diabetic mice. The expression of TNF- $\alpha$ and $I L-1 \beta$ mRNAs in the lumbar segment of the spinal cord of mice with diabetes was significantly increased 2 weeks after STZ injection (Figures 8A,B). The intraperitoneal administration of GNF-2 significantly decreased the diabetes-induced increase in the expression of pro-inflammatory cytokines such as TNF$\alpha$ and $I L-1 \beta$ mRNAs in the spinal cord tissues (Figure 8B). To evaluate the effects of GNF-2 on neuroinflammation, we also assessed diabetes-induced changes in glial activation and proliferation in the spinal cord using immunostaining. In diabetic mice, there was a significant increase in the number of Iba-1-positive microglial cells in the dorsal horn of the spinal cord tissues isolated from the lumbar segment, where the microglia displayed enhanced Iba-1 immunoreactivity with reactive morphological changes (Figure 8C). Similarly, the number of GFAP-positive astrocytes was markedly increased in the spinal cord dorsal horn of STZ-induced diabetic mice. This increase was accompanied by an increase in GFAP immunoreactivity and hypertrophic morphology with 


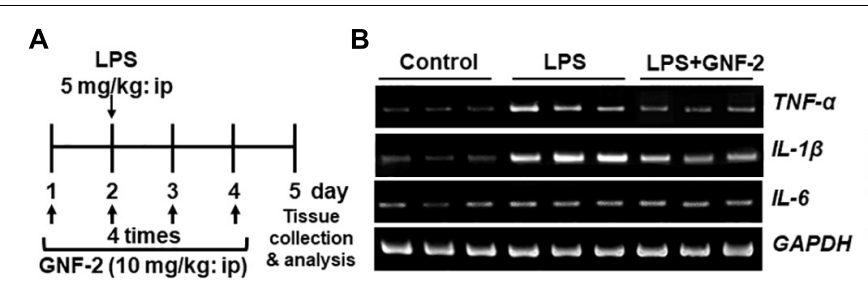

C
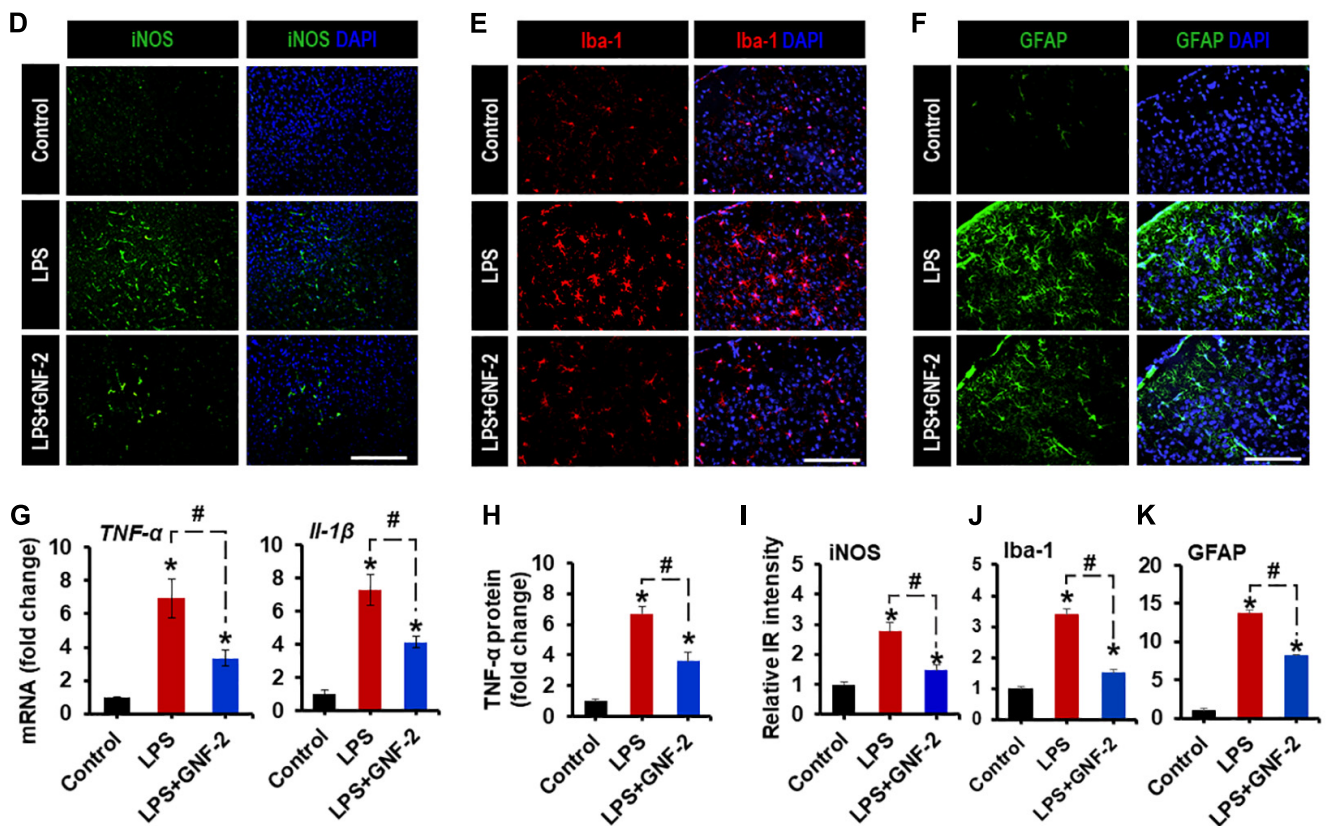

FIGURE 5 | Effects of GNF-2 administration on LPS-induced neuroinflammation in vivo. (A) To determine the role of c-Abl in neuroinflammation, GNF-2, and LPS were administered intraperitoneally at the indicated time points as shown in the experimental outline. (B) The expression of TNF- $\alpha$ and IL-1 $\beta$ mRNAs in the brain tissues after GNF-2 and LPS injection was evaluated by conventional RT-PCR. (C) The western blot detection of TNF- $\alpha$ protein in the brain tissue after GNF-2 and LPS injection. (D-F) The immunoreactivity (IR) of iNOS, Iba-1, and GFAP was increased in the brain of LPS-injected mice, whereas GNF-2 administration significantly attenuated this increase in IR. The nuclei were stained with DAPI. (G) Quantification for the TNF- $\alpha$ and IL-1 $\beta$ mRNA expression is displayed as the fold change of gene expression normalized to GAPDH. (H) Quantification for the TNF- $\alpha$ protein from the western blot. (I-K) Quantification for the relative intensities of iNOS, Iba-1, and GFAP IR is presented in the graph. ${ }^{*} p<0.05$ vs. vehicle-treated control animals; ${ }^{*} p<0.05$ between the indicated groups; unpaired two-tailed Student's $t$ test; $n=3$ for each group; data are presented as mean \pm SEM. Scale bar $400 \mu \mathrm{m}$ (D), $200 \mu \mathrm{m}$ (E,F).

thick processes (Figure 8D). Notably, GNF-2 administration significantly downregulated Iba-1 and GFAP immunoreactivity in the spinal cord of STZ-injected mice (Figures 8E,F). These results obtained through the pharmacological inhibition of $\mathrm{c}$-Abl demonstrate that $\mathrm{c}$-Abl plays a crucial role in diabetesassociated neuroinflammation.

Furthermore, the contribution of $\mathrm{c}-\mathrm{Abl}$ activation to the pathogenesis of diabetic pain was assessed through the pharmacological inhibition of c-Abl. A single intraperitoneal injection of mice with GNF-2 (10 mg/kg) significantly attenuated diabetes-induced thermal hyperalgesia (Figure 9A) as well as mechanical allodynia (Figure 9B). However, the vehicle alone did not alter the withdrawal latency in response to thermal stimuli or withdrawal threshold in response to mechanical stimuli. These findings suggest that c-Abl plays a critical role in diabetes-induced neuroinflammation and associated pain hypersensitivity. Thus, GNF-2 might be a potent therapeutic agent for the treatment of chronic pain which results from diabetic peripheral neuropathy.

\section{DISCUSSION}

In this study, we show that the upregulation of c-Abl expression promotes the classical pro-inflammatory activation of microglia and that GNF-2, a potent c-Abl inhibitor, attenuates neuroinflammation and pain hypersensitivities in CFA- and STZ- induced pain models. Our findings demonstrate that c-Abl contributes to the pathogenesis of chronic pain by regulating microglial activation and neuroinflammation.

Chronic pain is caused by nerve damage which occurs during nerve compression, diabetes, inflammation, and shingles virus infection (Campbell and Meyer, 2006). Specifically, cytokines, chemokines, prostaglandins, and NO released from activated microglia and astrocytes in the dorsal horn of the spinal cord are known to play important roles in the pathogenesis of chronic pain (Skaper et al., 2012; Vega-Avelaira et al., 2013). Therefore, several studies have targeted activated microglia in order to reduce pain hypersensitivity (Hsieh et al., 2018). For example, treatment with minocycline, a microglial inhibitor, 
A
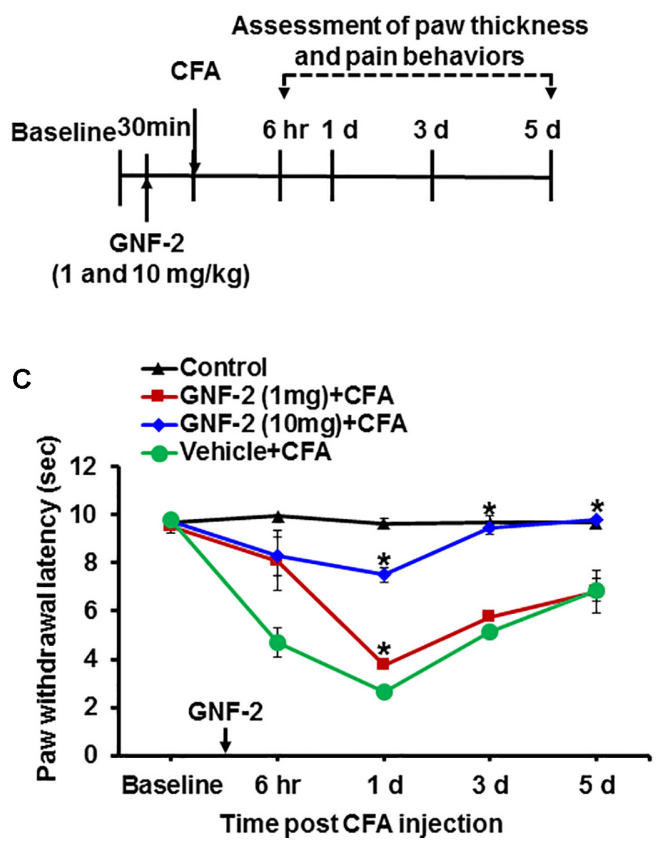
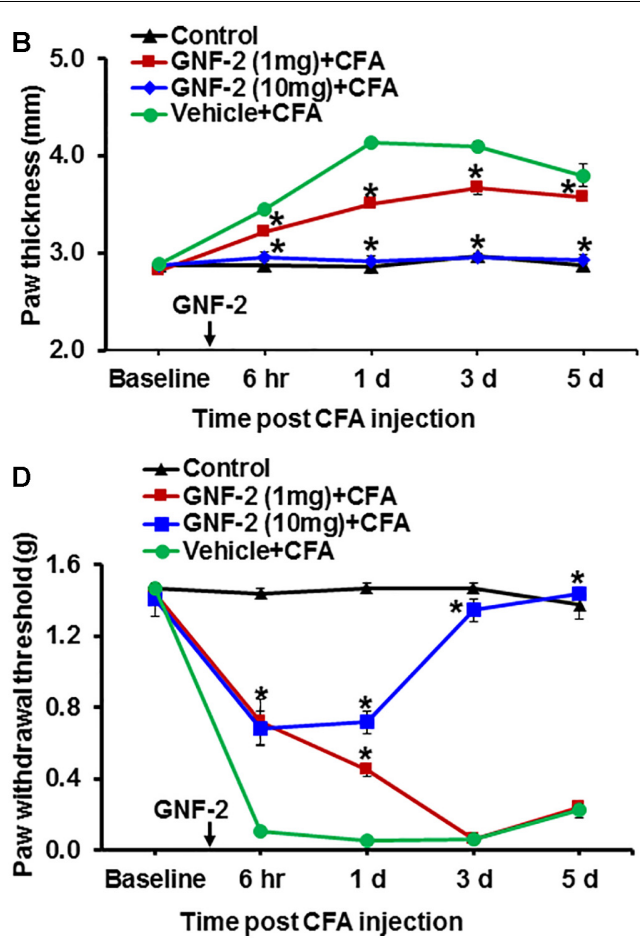

FIGURE 6 | Effects of GNF-2 on CFA-induced paw edema and inflammatory pain behaviors. (A) To investigate the role of c-Abl in CFA-induced inflammatory pain phenotypes, GNF-2 were administered into hind paw 30 min before the intraplantar injection of CFA at the indicated time points as shown in the experimental outline. Paw edema and pain responses were measured at 6 h, 1, 3, and 5 d post-CFA injection. In the ipsilateral sides, CFA injection increased paw thickness (B) and reduced PWL to heat (C) as well as PWT to force (D) when compared with vehicle-injected control animals. The CFA-induced paw edema and pain hypersensitivity were attenuated in the GNF-2-injected mice (1 and $10 \mathrm{mg} / \mathrm{kg}$ ) in a dose-dependent manner. No significant change in paw edema or pain-related behavior was observed in the contralateral sides and vehicle-injected animals. ${ }^{*} p<0.05$ vs. vehicle + CFA injected animals Student's $t$ test; $n=3$ for each group; data are represented as mean \pm SEM. d, day (s).

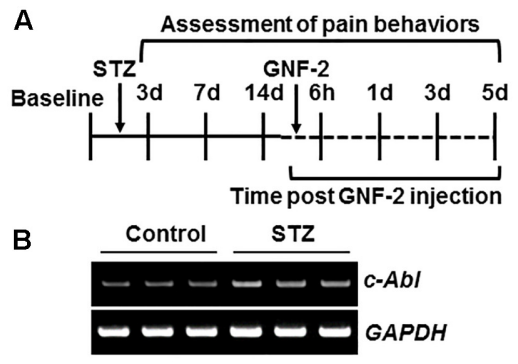

C

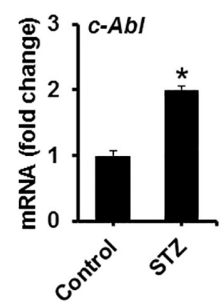

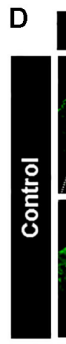
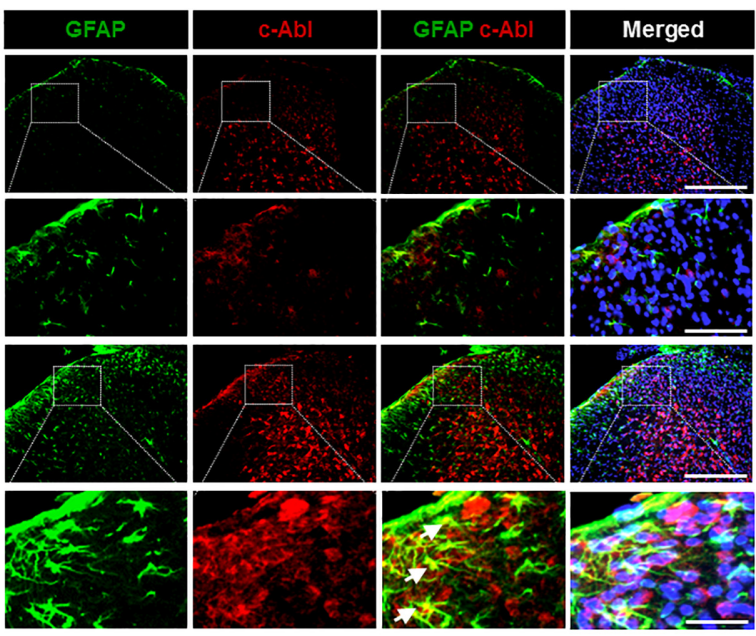

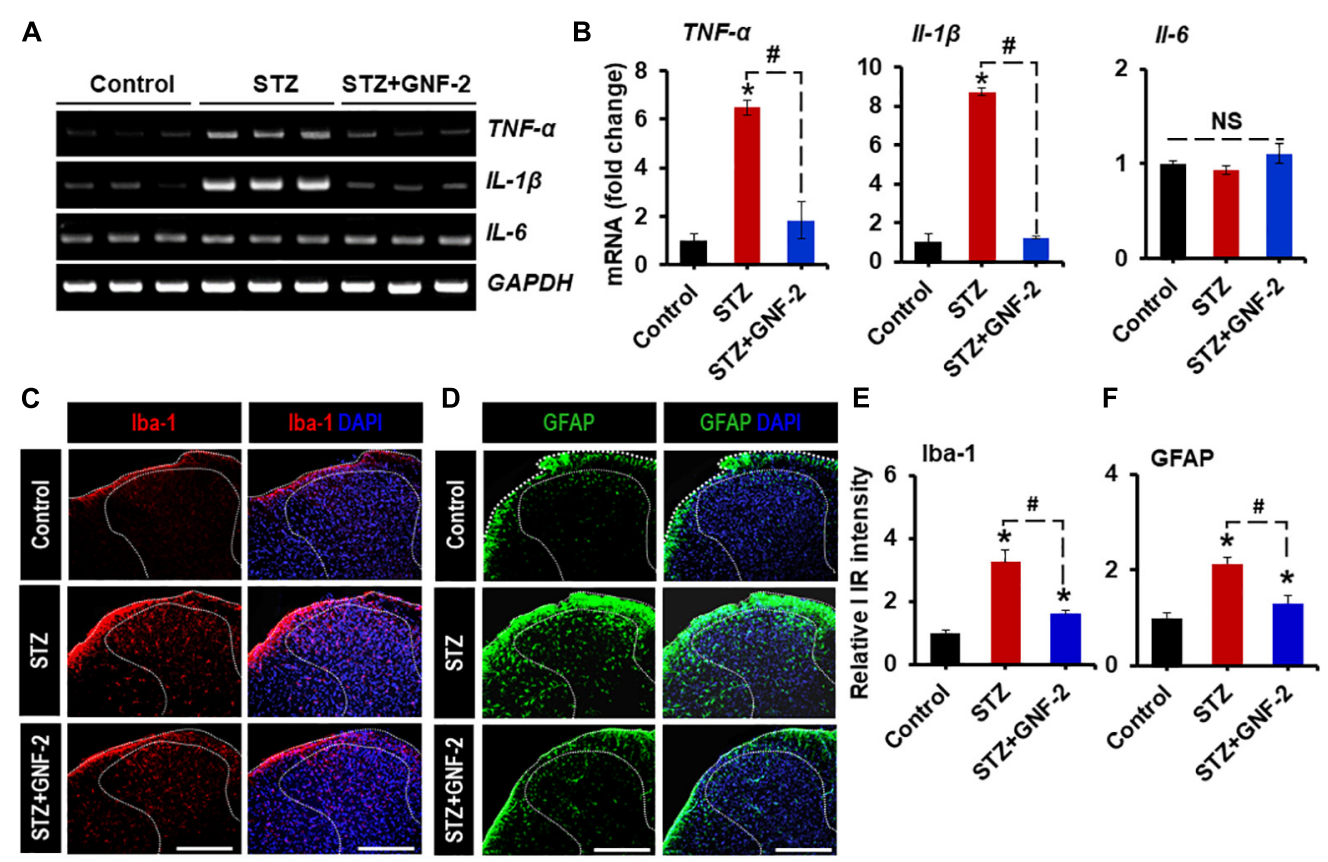

FIGURE 8 | GNF-2 attenuates STZ-induced neuroinflammation. (A) The expression of TNF- $\alpha$, IL-1 $\beta$, and IL-6 mRNAs in the spinal cord tissues after GNF-2 and STZ injection was evaluated by conventional RT-PCR. (B) Quantification for mRNA expression is displayed as the fold increase of gene expression normalized to Gapdh. (C,D) Immunoreactivity (IR) of Iba-1 and GFAP was increased in the spinal cord (L4-6) of LPS-injected mice, whereas GNF-2 administration significantly attenuated this increase in IR. (E,F) Quantification for the relative intensity of Iba-1 and GFAP IR is presented adjacent to the microscopic images. ${ }^{*} p<0.05$ vs. vehicle-treated control animals; ${ }^{\#} p<0.05$ between the indicated groups; unpaired two-tailed Student's $t$ test; $n=3$ for each group; data are represented as mean \pm SEM. Scale bar, $100 \mu \mathrm{m}$
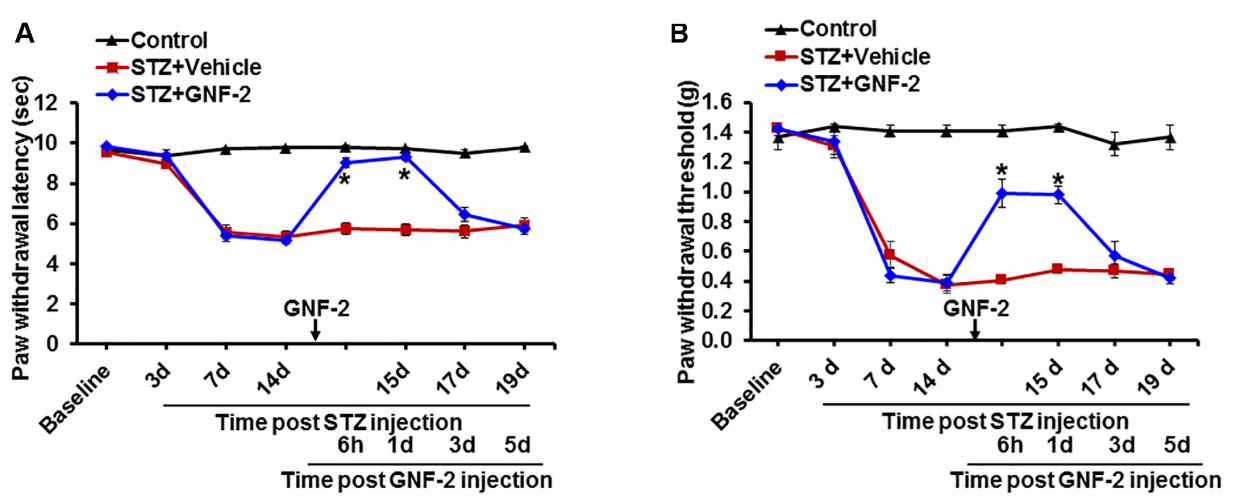

FIGURE 9 | Effects of GNF-2 on STZ-induced diabetic pain. To investigate the role of c-Abl in STZ-induced pain phenotypes, GNF-2 was administered intraperitoneally at the indicated time point. STZ injection reduced PWL to heat (A) as well as PWT to force (B) when compared with vehicle-injected control animals. The STZ-induced pain hypersensitivity was attenuated in the GNF-2-injected mice (10 mg/kg). No significant change in pain-related behavior was observed in the contralateral sides and vehicle injected animals. ${ }^{*} p<0.05$ vs. vehicle + STZ-injected animals Student's $t$ test; $n=3$ for each group; data are represented as mean \pm SEM. d, day (s).

prevents pain hypersensitivity caused by systemic LPS exposure in neonates, and its protective effect may be related to its ability to attenuate LPS-induced microglial activation, proinflammatory cytokine IL- $1 \beta$, and pain mediator $\mathrm{PGE}_{2}$. In addition, microglial activation is pivotal to the development and maintenance of allodynia after spinal cord injury through mechanisms involving both TNF- $\alpha$ and IL- $1 \beta$ and in chronic states, IL-6 (Detloff et al., 2008). Previous studies have shown that inflammation and oxidative stress are associated with the overexpression and activation of c-Abl (Schlatterer et al., 2011; Lawana et al., 2017). In fact, in our study, an increase in c-Abl expression was observed in the inflammatory pain models and glial activation and pain hypersensitivity were reduced by the c-Abl inhibitor.

The activation of $\mathrm{c}$-Abl has been reported to play a role in neurodegenerative diseases. For example, in $\mathrm{AD}$, 
beta-amyloid $(\mathrm{A} \beta)$ activates $\mathrm{c}$-Abl in hippocampal neurons (Alvarez et al., 2004) and c-Abl levels are increased in pre-tangle neurons in AD (Derkinderen et al., 2005). The inhibition of $\mathrm{c}-\mathrm{Abl}$ activity by Imatinib (STI-571) protects hippocampal neurons from $\mathrm{A} \beta$-induced apoptosis and the reduction of $\mathrm{c}-\mathrm{Abl} \mathrm{mRNA}$ levels protects neuronal cells from $\mathrm{A} \beta$-induced toxicity (Alvarez et al., 2004). Recently, it has been reported that the tyrosine phosphorylation of parkin by the oxidative stress-induced $\mathrm{c}$-Abl is part of a regulatory mechanism in parkin function (Imam et al., 2011). Tyrosine phosphorylation of parkin results in impaired E3-ubiquitin ligase activity and auto-ubiquitination of parkin. c-Abl activation also plays a key role in $\alpha$-synuclein neurodegeneration. c-Abl overexpression in mice leads to dopaminergic neuron degeneration and $\alpha$-synuclein pathologies, while c-Abl deletion reduces $\alpha$-synuclein pathologies. Activation of $\mathrm{c}$-Abl leads to tyrosine 39 phosphorylation of $\alpha$-synuclein, which strongly correlates with disease progression in hA53T $\alpha$-syn transgenic mice, suggesting a critical role of c-Abl in neuronal function and survival (Brahmachari et al., 2016).

The use of $\mathrm{c}$-Abl inhibitors such as imatinib and nilotinib have been proposed for the treatment of $\mathrm{AD}$ and PD. Indeed, there have been a few reports which indicated that c-Abl inhibition might be beneficial in PD and $\alpha$-synucleinopathies (Ko et al., 2010; Hebron et al., 2013). The c-Abl inhibitor, STI-571 (Imatinib), restores the E3 ligase activity of parkin and reduces the accumulation of parkin substrates, thereby protecting against 1-methyl-4-phenylpyridinium $(\mathrm{MPP}+)$-induced neurotoxicity in vitro (Ko et al., 2010; Imam et al., 2011). However, in the aforementioned studies, it was difficult to conclude whether c-Abl inhibition could be an effective neuroprotective strategy because of the lack of selectivity of the c-Abl inhibitors they used. Imatinib and nilotinib are potent inhibitors of tyrosine kinases which include c-Abl, Src families, c-Kit, and PDGFR. However, GNF-2, a third-generation c-Abl inhibitor, had no detectable inhibitory effect on the Src family kinases Hck, Lyn, Lck, and c-Src (Choi et al., 2009). Therefore, in the current study, we used GNF-2, which is a more specific c-Abl inhibitor, and siRNA to knockdown c-Abl gene expression in order to investigate the role of c-Abl in neuroinflammation and related pathology.

\section{REFERENCES}

Adrian, F. J., Ding, Q., Sim, T., Velentza, A., Sloan, C., Liu, Y., et al. (2006). Allosteric inhibitors of Bcr-abl-dependent cell proliferation. Nat. Chem. Biol. 2, 95-102. doi: 10.1038/nchembio760

Alvarez, A. R., Sandoval, P. C., Leal, N. R., Castro, P. U., and Kosik, K. S. (2004). Activation of the neuronal c-Abl tyrosine kinase by amyloid-beta-peptide and reactive oxygen species. Neurobiol. Dis. 17, 326-336. doi: 10.1016/j.nbd.2004. 06.007

Banks, W. A., Gray, A. M., Erickson, M. A., Salameh, T. S., Damodarasamy, M., Sheibani, N., et al. (2015). Lipopolysaccharide-induced blood-brain barrier disruption: roles of cyclooxygenase, oxidative stress, neuroinflammation, and elements of the neurovascular unit. J. Neuroinflammation 12:223. doi: 10.1186/ s12974-015-0434-431

Brahmachari, S., Ge, P., Lee, S. H., Kim, D., Karuppagounder, S. S., Kumar, M., et al. (2016). Activation of tyrosine kinase c-Abl contributes to

\section{CONCLUSION}

In conclusion, GNF-2 significantly inhibits NF- $\kappa$ B activation and LPS-induced pro-inflammatory molecules including TNF- $\alpha$ and $\mathrm{NO}$ in microglia and in vivo models of chronic inflammatory and neuropathic pain. Furthermore, we show that GNF-2 very efficiently prevents inflammatory and diabetic pain in animal models. Our results buttress the role of $\mathrm{c}-\mathrm{Abl}$ in the pathogenesis of neuroinflammatory diseases. These findings indicate that c-Abl can be therapeutically targeted for both the prevention and reversal of chronic pathological pain.

\section{ETHICS STATEMENT}

This study was carried out in accordance with the recommendations of Animal Care Committee of Kyungpook National University.

\section{AUTHOR CONTRIBUTIONS}

KS and GS: conceptualization. GS, MR, MJ, DG, SP, and J-HK: data acquisition and methodology. S-HL, TS, I-KL, YB, W-HL, GS, and KS: investigation. KS: project administration, resources, and supervision. GS and KS: validation. All authors wrote and edited the manuscript.

\section{FUNDING}

This work was supported by a grant from the Korea Healthcare Technology R\&D Project, Ministry of Health \& Welfare, South Korea (HI16C1501) and the Basic Science Research Program through the National Research Foundation (NRF), which is funded by the Korean government (MSIT) (2018R1A2A1A05077118, 2016M3C7A1904148, and NRF2017R1A5A2015391). GS was supported by the NRF grant (Grant No. 2016R1D1A1B01009186). TS was supported by the KU-KIST Graduate School of Converging Science and Technology Program.

alpha-synuclein-induced neurodegeneration. J. Clin. Invest. 126, 2970-2988. doi: $10.1172 /$ JCI85456

Calsolaro, V., and Edison, P. (2016). Neuroinflammation in Alzheimer's disease: current evidence and future directions. Alzheimers Dement. 12, 719-732. doi: 10.1016/j.jalz.2016.02.010

Campbell, J. N., and Meyer, R. A. (2006). Mechanisms of neuropathic pain. Neuron 52, 77-92. doi: 10.1016/j.neuron.2006.09.021

Cancino, G. I., Toledo, E. M., Leal, N. R., Hernandez, D. E., Yevenes, L. F., Inestrosa, N. C., et al. (2008). STI571 prevents apoptosis, tau phosphorylation and behavioural impairments induced by Alzheimer's beta-amyloid deposits. Brain 131(Pt 9), 2425-2442. doi: 10.1093/brain/ awn 125

Carniglia, L., Ramirez, D., Durand, D., Saba, J., Turati, J., Caruso, C., et al. (2017). Neuropeptides and microglial activation in inflammation, pain, and neurodegenerative diseases. Mediators Inflamm. 2017:5048616. doi: 10.1155/ $2017 / 5048616$ 
Chen, G., Zhang, Y. Q., Qadri, Y. J., Serhan, C. N., and Ji, R. R. (2018). Microglia in pain: detrimental and protective roles in pathogenesis and resolution of pain. Neuron 100, 1292-1311. doi: 10.1016/j.neuron.2018.11.009

Choi, Y., Seeliger, M. A., Panjarian, S. B., Kim, H., Deng, X., Sim, T., et al. (2009). $\mathrm{N}$-myristoylated c-Abl tyrosine kinase localizes to the endoplasmic reticulum upon binding to an allosteric inhibitor. J. Biol. Chem. 284, 29005-29014. doi: 10.1074/jbc.M109.026633

Derkinderen, P., Scales, T. M., Hanger, D. P., Leung, K. Y., Byers, H. L., Ward, M. A., et al. (2005). Tyrosine 394 is phosphorylated in Alzheimer's paired helical filament tau and in fetal tau with $\mathrm{c}-\mathrm{Abl}$ as the candidate tyrosine kinase. J. Neurosci. 25, 6584-6593. doi: 10.1523/JNEUROSCI.1487-05.2005

Detloff, M. R., Fisher, L. C., McGaughy, V., Longbrake, E. E., Popovich, P. G., and Basso, D. M. (2008). Remote activation of microglia and pro-inflammatory cytokines predict the onset and severity of below-level neuropathic pain after spinal cord injury in rats. Exp. Neurol. 212, 337-347. doi: 10.1016/j.expneurol. 2008.04.009

Fabbro, D., Manley, P. W., Jahnke, W., Liebetanz, J., Szyttenholm, A., Fendrich, G., et al. (2010). Inhibitors of the Abl kinase directed at either the ATP- or myristate-binding site. Biochim. Biophys. Acta 1804, 454-462. doi: 10.1016/j. bbapap.2009.12.009

Frank-Cannon, T. C., Alto, L. T., McAlpine, F. E., and Tansey, M. G. (2009). Does neuroinflammation fan the flame in neurodegenerative diseases? Mol. Neurodegener. 4:47. doi: 10.1186/1750-1326-4-47

Hebron, M. L., Lonskaya, I., and Moussa, C. E. (2013). Nilotinib reverses loss of dopamine neurons and improves motor behavior via autophagic degradation of alpha-synuclein in Parkinson's disease models. Hum. Mol. Genet. 22, 33153328. doi: 10.1093/hmg/ddt192

Hsieh, C. T., Lee, Y. J., Dai, X., Ojeda, N. B., Lee, H. J., Tien, L. T., et al. (2018). Systemic lipopolysaccharide-induced pain sensitivity and spinal inflammation were reduced by minocycline in neonatal Rats. Int. J. Mol. Sci. 19:2947. doi: 10.3390/ijms19102947

Imam, S. Z., Zhou, Q., Yamamoto, A., Valente, A. J., Ali, S. F., Bains, M., et al. (2011). Novel regulation of parkin function through c-Abl-mediated tyrosine phosphorylation: implications for Parkinson's disease. J. Neurosci. 31, 157-163. doi: 10.1523/JNEUROSCI.1833-10.2011

Jangula, A., and Murphy, E. J. (2013). Lipopolysaccharide-induced blood brain barrier permeability is enhanced by alpha-synuclein expression. Neurosci. Lett. 551, 23-27. doi: 10.1016/j.neulet.2013.06.058

Jha, M. K., Jeon, S., Jin, M., Ock, J., Kim, J. H., Lee, W. H., et al. (2014). The pivotal role played by lipocalin-2 in chronic inflammatory pain. Exp. Neurol. 254, 41-53. doi: 10.1016/j.expneurol.2014.01.009

Jha, M. K., Rahman, M. H., Park, D. H., Kook, H., Lee, I. K., Lee, W. H., et al. (2016). Pyruvate dehydrogenase kinase 2 and 4 gene deficiency attenuates nociceptive behaviors in a mouse model of acute inflammatory pain. J. Neurosci. Res. 94, 837-849. doi: 10.1002/jnr.23727

Jha, M. K., Song, G. J., Lee, M. G., Jeoung, N. H., Go, Y., Harris, R. A., et al. (2015). Metabolic connection of inflammatory pain: pivotal role of a pyruvate dehydrogenase kinase-pyruvate dehydrogenase-lactic acid axis. J. Neurosci. 35, 14353-14369. doi: 10.1523/JNEUROSCI.1910-15.2015

Jo, M., Kim, J. H., Song, G. J., Seo, M., Hwang, E. M., and Suk, K. (2017). Astrocytic orosomucoid-2 modulates microglial activation and neuroinflammation. J. Neurosci. 37, 2878-2894. doi: 10.1523/JNEUROSCI.2534-16.2017

Katsulov, A., and Mazneikova, V. (1987). Treatment of eclamptic convulsions with the so-called lytic cocktail. Akush. Ginekol. 26, 71-74.

Katsumata, R., Ishigaki, S., Katsuno, M., Kawai, K., Sone, J., Huang, Z., et al. (2012). c-Abl inhibition delays motor neuron degeneration in the G93A mouse, an animal model of amyotrophic lateral sclerosis. PLoS One 7:e46185. doi: 10.1371/journal.pone.0046185

Kiguchi, N., Kobayashi, D., Saika, F., Matsuzaki, S., and Kishioka, S. (2017). Pharmacological regulation of neuropathic pain driven by inflammatory macrophages. Int. J. Mol. Sci. 18:2296. doi: 10.3390/ijms18112296

Ko, H. S., Lee, Y., Shin, J. H., Karuppagounder, S. S., Gadad, B. S., Koleske, A. J., et al. (2010). Phosphorylation by the c-Abl protein tyrosine kinase inhibits parkin's ubiquitination and protective function. Proc. Natl. Acad. Sci. U.S.A. 107, 16691-16696. doi: 10.1073/pnas.1006083107

Lawana, V., Singh, N., Sarkar, S., Charli, A., Jin, H., Anantharam, V., et al. (2017). Involvement of c-Abl kinase in microglial activation of NLRP3 inflammasome and impairment in autolysosomal system. J. Neuroimmune Pharmacol. 12, 624-660. doi: 10.1007/s11481-017-9746-9745
Lee, S., Park, J. Y., Lee, W. H., Kim, H., Park, H. C., Mori, K., et al. (2009). Lipocalin2 is an autocrine mediator of reactive astrocytosis. J. Neurosci. 29, 234-249. doi: 10.1523/JNEUROSCI.5273-08.2009

Mikitsh, J. L., and Chacko, A. M. (2014). Pathways for small molecule delivery to the central nervous system across the blood-brain barrier. Perspect. Medicin. Chem. 6, 11-24. doi: 10.4137/PMC.S13384

Mosley, R. L., Benner, E. J., Kadiu, I., Thomas, M., Boska, M. D., Hasan, K., et al. (2006). Neuroinflammation, oxidative stress and the pathogenesis of Parkinson's disease. Clin. Neurosci. Res. 6, 261-281. doi: 10.1016/j.cnr.2006. 09.006

Rahman, M. H., Jha, M. K., Kim, J. H., Nam, Y., Lee, M. G., Go, Y., et al. (2016). Pyruvate dehydrogenase kinase-mediated glycolytic metabolic shift in the dorsal root ganglion drives painful diabetic neuropathy. J. Biol. Chem. 291, 6011-6025. doi: 10.1074/jbc.M115.699215

Rossari, F., Minutolo, F., and Orciuolo, E. (2018). Past, present, and future of Bcr-Abl inhibitors: from chemical development to clinical efficacy. J. Hematol. Oncol. 11:84. doi: 10.1186/s13045-018-0624-622

Schlatterer, S. D., Tremblay, M. A., Acker, C. M., and Davies, P. (2011). Neuronal c-Abl overexpression leads to neuronal loss and neuroinflammation in the mouse forebrain. J. Alzheimers Dis. 25, 119-133. doi: 10.3233/JAD-2011102025

Skaper, S. D., Giusti, P., and Facci, L. (2012). Microglia and mast cells: two tracks on the road to neuroinflammation. FASEB J. 26, 3103-3117. doi: 10.1096/fj.11197194

Song, G. J., Nam, Y., Jo, M., Jung, M., Koo, J. Y., Cho, W., et al. (2016). A novel small-molecule agonist of PPAR-gamma potentiates an anti-inflammatory M2 glial phenotype. Neuropharmacology 109, 159-169. doi: 10.1016/j.neuropharm. 2016.06.009

Song, G. J., and Suk, K. (2017). Pharmacological modulation of functional phenotypes of microglia in neurodegenerative diseases. Front. Aging Neurosci. 9:139. doi: 10.3389/fnagi.2017.00139

Tanaka, T., and Iino, M. (2016). Nuclear translocation of p65 is controlled by sec6 via the degradation of ikappaBalpha. J. Cell. Physiol. 231, 719-730. doi: $10.1002 /$ jcp. 25122

Tansey, M. G., McCoy, M. K., and Frank-Cannon, T. C. (2007). Neuroinflammatory mechanisms in Parkinson's disease: potential environmental triggers, pathways, and targets for early therapeutic intervention. Exp. Neurol. 208, 1-25. doi: 10.1016/j.expneurol.2007.07.004

Varatharaj, A., and Galea, I. (2017). The blood-brain barrier in systemic inflammation. Brain Behav. Immun. 60, 1-12. doi: 10.1016/j.bbi.2016.03.010

Vargas, L. M., Cerpa, W., Munoz, F. J., Zanlungo, S., and Alvarez, A. R. (2018). Amyloid-beta oligomers synaptotoxicity: the emerging role of EphA4/c-Abl signaling in Alzheimer's disease. Biochim. Biophys. Acta Mol. Basis Dis. 1864(4 Pt A), 1148-1159. doi: 10.1016/j.bbadis.2018.01.023

Vega-Avelaira, D., Ballesteros, J. J., and Lopez-Garcia, J. A. (2013). Inflammationinduced hyperalgesia and spinal microglia reactivity in neonatal rats. Eur. J. Pain 17, 1180-1188. doi: 10.1002/j.1532-2149.2013.00308.x

Xiao, L., Chen, D., Hu, P., Wu, J., Liu, W., Zhao, Y., et al. (2011). The c-Abl-MST1 signaling pathway mediates oxidative stress-induced neuronal cell death. J. Neurosci. 31, 9611-9619. doi: 10.1523/JNEUROSCI.0035-11. 2011

Zhang, J., Adrian, F. J., Jahnke, W., Cowan-Jacob, S. W., Li, A. G., Iacob, R. E., et al. (2010). Targeting Bcr-Abl by combining allosteric with ATP-binding-site inhibitors. Nature 463, 501-506. doi: 10.1038/nature 08675

Conflict of Interest Statement: S-HL was employed by company VORONOI Inc.

The remaining authors declare that the research was conducted in the absence of any commercial or financial relationships that could be construed as a potential conflict of interest.

Copyright (C) 2019 Song, Rahman, Jha, Gupta, Park, Kim, Lee, Lee, Sim, Bae, Lee and Suk. This is an open-access article distributed under the terms of the Creative Commons Attribution License (CC BY). The use, distribution or reproduction in other forums is permitted, provided the original author(s) and the copyright owner(s) are credited and that the original publication in this journal is cited, in accordance with accepted academic practice. No use, distribution or reproduction is permitted which does not comply with these terms. 